\title{
Similarity yet a range of differences between humpback whale songs recorded in the Philippines, Japan and Hawaii in 2006
}

\author{
James D. Darling ${ }^{1, *}$, Jo Marie V. Acebes ${ }^{2}$, Manami Yamaguchi ${ }^{3}$ \\ ${ }^{1}$ Whale Trust, PO Box 243, Makawao, Hawaii 96768, USA \\ ${ }^{2}$ Balyena.org, Brgy. Pangdan, Jagna, Bohol, 6300, Philippines \\ ${ }^{3}$ Ogasawara Club, Coffee Mountain, Komagari, Chichi-jima, Ogasawara, Tokyo, 100-2101, Japan
}

\begin{abstract}
Humpback whale Megaptera novaeangliae songs have been proposed as a means to define stocks or coherent population units, based on the assumption that if individuals sing the same complex, ever-changing song, then they must associate. Songs from the Philippines (Babuyan Islands), Japan (Ogasawara) and Hawaii in 2006 were compared to examine the relationship of these populations as determined by song composition. A total of 13 phrases (including phrase variants) were identified from the sample overall. Philippine and Japan songs were composed of the same 9 phrases, while Hawaii song had these 9 phrases, plus 4 unique phrases. Common phrases were presented by singers in the same pattern in all 3 regions. Comparison of phrase use and proportion found a high correlation between the Philippines and Japan $(\mathrm{r}=0.876$, $\mathrm{p}<$ $0.001)$, and moderate correlations between Japan and Hawaii $(r=0.583, p=0.029)$ and the Philippines and Hawaii $(\mathrm{r}=0.570, \mathrm{p}=0.033)$. With the Japan and Philippines sites $2300 \mathrm{~km}$ apart and 6200 and $8400 \mathrm{~km}$ from Hawaii, respectively, this suggests a relationship between degree of separation and degree of song difference. The range of differences between songs is consistent with a 2-stage splitting of the migratory stream into separate winter assemblies where song divergence may occur. Partial similarity of song (versus entirely same or different) suggests some components are more sensitive to change than others. The variable pace of change may complicate use of song as an index of recent association, especially between populations with different social circumstances that presumably govern song change.
\end{abstract}

KEY WORDS: Humpback whale $\cdot$ Megaptera novaeangliae $\cdot$ Song · Population comparisons · Philippines · Japan · Hawaii

\section{INTRODUCTION}

Humpback whale males broadcast a repetitive, complex sequence of sounds known as song (Payne \& McVay 1971). A defining characteristic of this song is that its composition - that is, the presence, arrangement and repetition of different sound units - progressively changes as it is being sung, yet most singers in a population tend to sing the same version at any one time (Payne et al.1983). Although the dynamic is not understood, singers apparently change their own song to be similar to others around them,

${ }^{*}$ Corresponding author: jimd367@gmail.com and for some reason this song-matching process is important.

This behavior has been proposed as a means of defining stocks or other significant population units (Winn et al. 1981, Payne \& Guinee 1983, Noad et al. 2000, Cerchio et al. 2001, Darling \& Sousa-Lima 2005, Garland et al. 2011, Murray et al. 2012). The working assumption is that if whales sing the same version of the complex, ever-changing song then they must have associated at some recent point in time. This identity-by-song may occur across entire ocean basins, such as in the eastern North Pacific

() The authors 2014. Open Access under Creative Commons by Attribution Licence. Use, distribution and reproduction are unrestricted. Authors and original publication must be credited. 
(Winn et al. 1981, Payne \& Guinee 1983, Cerchio et al. 2001) and in the South Atlantic (Darling \& SousaLima 2005), between Southern Hemisphere oceans (Noad et al. 2000) or within more limited regions, such as one archipelago in the South Pacific (Garland et al. 2011). The factors determining the extent of a population defined by a specific song are not known.

On a broad scale, the structure of the humpback whale song has been fairly consistent in all investigations to date (Cholewiak et al. 2013). It is composed of several different sound units arranged as a phrase that is repeated as a theme (Payne \& McVay 1971). Typically, 4 to 9 distinct themes compose the song. Once a whale has sung through its current repertoire of themes, taking about 5 to 20 min to do so, it repeats the song cycle. Within this consistent song structure, the specific sound units utilized and their arrangement, change. The pace of change varies from gradual and incremental, taking up to 5 yr for complete turnover (Payne \& Payne 1985), to rapid, wholesale shifts in composition forming an entirely new song in 2 yr (Noad et al. 2000). The key factor is that, essentially, all the singers in a population make the same changes. Considering the possible variations in the use and arrangements of multiple sounds, and the fact that the song is continually changing in every population, simultaneous similarities must be the result of interaction.

Current understanding of song-based North Pacific humpback whale population definition has come mostly from studies comparing songs from Mexico and Hawaii winter assemblies. The songs were found to be markedly similar to identical_-indicating that mixing occurs throughout the northeast Pacific basin (Winn et al. 1981, Payne \& Guinee 1983, Cerchio et al. 2001). Comparisons of songs from western North Pacific winter assemblies with those of Hawaii (and further east) have been cursory to date, however, with a consistent result of partial overlap in composition. In a comparison of 1988 songs, the Japan (Ogasawara) song consisted of 5 of the 6 themes found in Hawaii (Darling \& Mori 1993); and in a comparison of 2003 songs, Philippine (Babuyan Islands) song shared 7 of 9 themes found in Hawaii (Acebes et al. 2007). A comparison of 1989 songs from Japan, Hawaii and Mexico reported greater differences between all 3 regions than the other studies, but still with some themes in common (Helweg et al. 1990). Overall these were very small sample size comparisons (as few as 1 song) and not deemed definitive beyond indicating that, due to shared themes, some interaction must occur between western and central North Pacific humpback populations.
Songs from different populations that are either identical or entirely different in composition have straightforward interpretations in terms of population identity (e.g. Winn et al. 1981, Payne \& Guinee 1983, Darling \& Sousa-Lima 2005). However, when songs from different populations show a partial overlap - that is, include themes common to both populations as well as themes that are unique to each, a new dimension is added. Hints of this possibility of partial similarity arose from preliminary comparisons of songs from Japan and Hawaii and the Philippines and Hawaii, as described above. In addition, Helweg et al. (1998) reported a partial similarity of songs from Eastern Australia, New Caledonia and Tonga, where 7 of 9 themes were shared. More recently, partial similarity was reported in 2006 songs from Madagascar and western Australia, where the samples from the 2 regions had only 1 of 5 themes in common (Murray et al. 2012).

The purpose of this study was to further investigate the relationship of western and central North Pacific humpback populations as portrayed by song composition, and in particular, to investigate whether the degree of difference in song correlates with the degree of separation of populations. Three geographically separate breeding assemblies within the North Pacific were chosen for a concurrent song comparison. Two, Japan and Philippines, are substantially closer together than either is to the third, Hawaii.

\section{MATERIALS AND METHODS}

\section{Study locations}

The 3 populations of humpback whales whose songs were compared were located near the Babuyan Islands in the northern Philippines $\left(19^{\circ} 01^{\prime} \mathrm{N}\right.$, $\left.121^{\circ} 38^{\prime} \mathrm{E}\right)$, the Ogasawara Islands, $960 \mathrm{~km}$ southeast of Tokyo, Japan $\left(27^{\circ} 05^{\prime} \mathrm{N}, 142^{\circ} 04^{\prime} \mathrm{E}\right)$ and Maui in the Hawaiian Islands $\left(20^{\circ} 45^{\prime} \mathrm{N}, 156^{\circ} 40^{\prime} \mathrm{W}\right)$ (Fig. 1). Hawaii is approximately 3 to 4 times further away than the Asian locations are from each other. In addition, songs recorded from American Samoa (14 $19^{\prime} \mathrm{S}$, $170^{\circ} 40^{\prime} \mathrm{W}$ ) were used as a point of comparison. The distance from Hawaii to American Samoa is less than between Hawaii and the Asian locations - but the Hawaii and American Samoa whale populations are separated by hemisphere and opposite migratory seasons. 


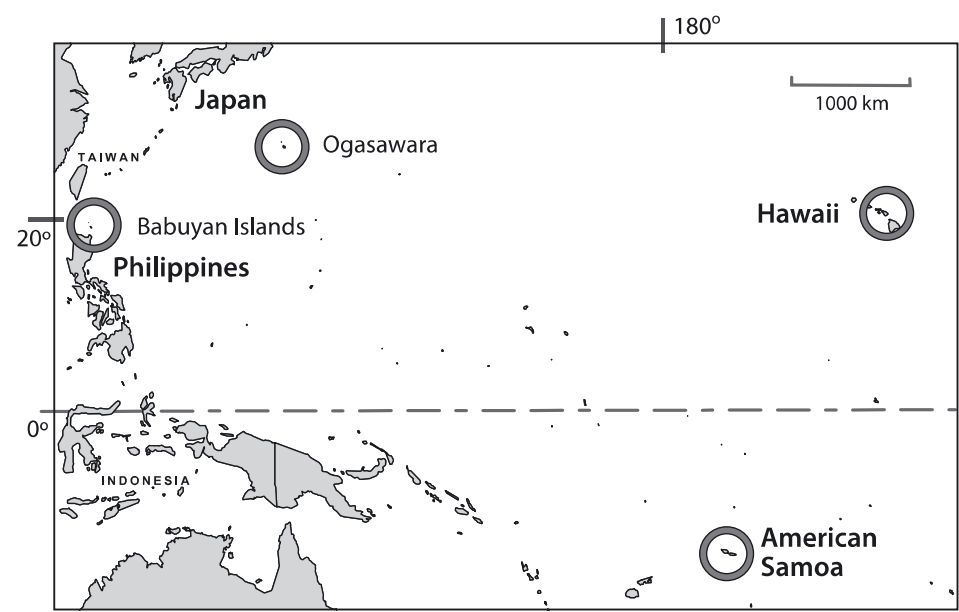

Fig. 1. The study areas in the Philippines, Japan, Hawaii and American Samoa where humpback whale song recordings were collected in 2006. The approximate distances between the locations are: Babuyan Islands to Ogasawara, $2300 \mathrm{~km}$; Ogasawara to Hawaii, $6200 \mathrm{~km}$; Babuyan Islands to Hawaii, 8400 km; and Hawaii to American Samoa 4200 km

\section{Sample of songs}

Humpback whale songs were recorded concurrently in each of the North Pacific locations, with a preseason objective of at least 3 to 5 different singers in each location. Recordings were a minimum of 20 min long to ensure collection of a complete song cycle. In the North Pacific, songs were recorded between February and April 2006 in the Babuyan Islands, Philippines by J. M. V. A. and Elson Aca, in Ogasawara, Japan by M. Y. and in Hawaii by J. D. D. Songs were recorded in American Samoa in October 2006 by David Matilla and Jooke Robbins.

Songs used in analyses were chosen from the collection of recordings from each site based on overall quality, largely determined by the degree of clarity of all song units. Recordings of 2 or more equidistant singers or 'choruses', as well as those with substantial background noise (waves, ships, etc.) were not used. Table 1 provides the song sample analyzed: 3 singers in Philippines, 4 singers in Japan and 9 singers in Hawaii. We acknowledge that this is a relatively small sample of songs considering the size of the whale populations; the assumption was made that this sample adequately represents the song composition of the whale populations compared.

\section{Terms}

The songs were described in the context of the hierarchical structure (sound units arranged as phrases repeated as a theme) and terms presented by Payne \& McVay (1971) and used by most investigators since that time (e.g. Noad et al. 2000, Cerchio et al. 2001, Darling \& SousaLima 2005, Garland et al. 2011, Murray et al. 2012). There has been some variation in the extent and definition of terms used by different investigators (these are reviewed in Cholewiak et al. 2013). The terms used in this paper are as follows:

Song cycle-one sequence of all phrases a singer is currently using, before repeating; often (but not always) begins with a dive and ends with next surfacing.

Unit_-single distinguishable, continual sound (as audible to human ear).

Phrase-sound units in a specific repetitive arrangement, usually (but not necessarily) composed of several different sounds.

Phrase variant - a slightly different version of the same phrase with 'minor' modification of units in the

Table 1. Humpback whale songs recorded in the Philippines, Japan, Hawaii and American Samoa in 2006 used for comparisons in this study. Bold numbers indicate combined duration of recordings. Letters following Hawaii March 26 indicate different singers recorded on the same day

\begin{tabular}{|c|c|c|c|}
\hline Location & Date & Recording length (s) & Full song cycles (s) \\
\hline $\begin{array}{l}\text { Philippines } \\
\text { (Babuyan Islands) }\end{array}$ & $\begin{array}{l}\text { Feb } 28 \\
\text { Mar } 22 \\
\text { Mar } 23\end{array}$ & $\begin{array}{c}2700 \\
3890 \\
2480 \\
\text { Total: } \mathbf{2} \mathbf{h} \mathbf{1 1} \mathbf{m i n} \mathbf{5 0} \mathbf{s}\end{array}$ & $\begin{array}{c}1(1470) \\
1(1075) \\
3(575)(525)(805)\end{array}$ \\
\hline $\begin{array}{l}\text { Japan } \\
\text { (Ogasawara) }\end{array}$ & $\begin{array}{l}\text { Feb } 27 \\
\text { Mar } 12 \\
\text { Mar } 15 \\
\text { Apr } 13\end{array}$ & $\begin{array}{c}2500 \\
3600 \\
1400 \\
1935 \\
\text { Total: } \mathbf{2} \mathbf{h} \mathbf{3 7} \mathbf{m i n} \mathbf{1 5} \mathbf{~ s}\end{array}$ & $\begin{array}{c}2(1145)(1240) \\
1(790) \\
1(1005) \\
2(1355)(990)\end{array}$ \\
\hline $\begin{array}{l}\text { Hawaii } \\
\text { (Maui) }\end{array}$ & $\begin{array}{c}\text { Feb } 15 \\
\text { Feb } 22 \\
\text { Feb } 26 \\
\text { Mar } 6 \\
\text { Mar 24 } \\
\text { Mar 25 } \\
\text { Mar } 26 \text { (A) } \\
\text { Mar } 26 \text { (C) } \\
\text { Apr } 3\end{array}$ & $\begin{array}{c}1760 \\
1190 \\
1380^{\mathrm{a}} \\
850 \\
1580 \\
875 \\
1400 \\
1950 \\
2835 \\
\text { Total: } \mathbf{3} \mathbf{h} \mathbf{5 0} \mathbf{m i n} \mathbf{2 0 ~ s}\end{array}$ & $\begin{array}{c}4(480)(480)(395)(405) \\
1(830) \\
0 \\
1(850) \\
1(880) \\
1(875) \\
1(1400) \\
1(1150) \\
2(1335)(1100)\end{array}$ \\
\hline American Samoa & Oct 6 & $\begin{array}{cl} & 1090 \\
\text { Total: } \mathbf{1 8} \mathbf{~ m i n ~} \mathbf{1 0} \mathbf{~ s}\end{array}$ & $2(390)(430)$ \\
\hline
\end{tabular}


sequence (e.g. if separate units run together). Note: when the term phrases is used in the text it refers collectively to the phrases and their variants.

Theme-segment of song that comprises repetition of the same phrase (including its variants). In this paper, theme is used as a term referring to all the repetitions of one phrase.

Transition - a short (typically seconds long) segment of the song where the whale shifts from one theme to the next and may mix sound units from both.

Hybrid phrase - a distinctive phrase composed of units from 2 other phrases in the song. A hybrid phrase typically recurs in a sample and is of longer duration than a transition.

\section{Categorization of sound patterns}

In any song analysis, there are different scales of comparison from coarse to fine. A coarser scale forgives small differences, lumping similar phrases together even, for example, when 2 units run together, or one unit is sporadically 'missing'. Finer scales split all variations of phrases (however minor to human ears) into separate categories. This study used a fine-scale analysis to help identify the level of detail at which regional differences may exist.

In this qualitative analysis a separate category was assigned to each phrase clearly composed of different sound units. Each phrase variant was also given its own category (with 1 exception involving combinations of multiple variants in 1 phrase explained in 'Results'). The relative occurrence of a sound pattern was also considered when defining phrases. If a pattern occurred for a few seconds once in the entire sample it was given less weight (and other than noted on the spectrogram, ignored) than if it occurred for a substantial proportion of the song and/or in multiple different singers. While there was some subjectivity in delineating phrases for comparison, once defined, categorization was consistent across all samples.

Songs were analyzed using Avisoft-SASLab Pro software. Spectrograms of each recording were made and phrases defined. In this analysis, transitions were simply divided, their time split between preceding and following themes. The different song phrases used in the comparisons were labeled alphanumerically in the general order of their occurrence in the song and by color, approximately reflecting degree of similarity. That is, phrases deemed 'different' but very similar (i.e. in a coarse analysis could be lumped) were labeled as variants of a numbered phrase (5a,5b and so on) and given shades of the same color (e.g. green) (see Fig. 2). Most phrases and variants were readily recognizable and consistent in all songs.

\section{Comparisons}

The song samples from the 3 regions, Philippines, Japan and Hawaii, were compared to determine: (1) the presence of specific phrases; (2) the order in which phrase variants were presented; and (3) the percent of the song cycle dedicated to the different phrases and their variants.

A primary question was: did a specific phrase exist in the population and if so, how common was it? This analysis investigated song similarities and differences between populations - not between individual singers. The sample of songs collected from each region was pooled to help ensure that comparisons were not affected by singer variability.

Any individual singer can omit a theme (that is, the repetition of a specific phrase) in a particular song cycle (and include it in the next cycle) and although the rule is that singers across a population sing strikingly similar songs, there is some variation.

Most raw song recordings included both complete song cycles and incomplete cycles, depending on when the recorder was started and stopped. Full recordings, including both full song cycles and fragments (i.e. all data available), were used to compare the presence or absence of a phrase in a region. This maximized the possibility of not missing a phrase that might have been caught in fragments but not in whole song. The full sample was also used to analyze the order of themes. However, only complete songs were used to analyze the proportion of each phrase in the song cycle to avoid the possibility that song fragments may, by chance, not represent all phrases fairly.

To investigate the degree of song similarity between the different regions, a correlation analysis was undertaken using the presence and proportion of the various phrases in the pooled sample from each location. Only full song cycles were used in this analysis (Table 1). In cases where more than 1 song was recorded from 1 singer, the mean portion of the song dedicated to each phrase was taken to provide 1 value per singer. All the singers in a region were then averaged to get 1 value for each phrase per region. 


\section{RESULTS}

\section{Presence of specific phrases}

For the purposes of this comparison, 13 different phrases (including phrase variants) were defined from the 3 regions collectively. In a coarser analysis, these could be reduced to 6 'themes' ( 2 themes had 2 phrase variants, 1 theme had 4 variants, and there were 2 hybrid phrases). Fig. 2 illustrates the phrases present in each location coded by color and alphanumerically. The spectrograms that form the basis of this figure are provided in the Appendix. The Philippines and Japan songs were composed of the same 9 (of the 13 total) phrases, while the Hawaii sample had all 13 phrases. That is, the Hawaii sample included the 9 phrases present in the Asian locations, as well as 4 others. This figure does not address the proportion of each theme in the sample, only whether or not it was present in a region.

To examine composition in more detail, the full individual recordings used in this analysis, with phrases color-coded, are provided in Fig. 3. Most striking is the similarity between the songs. However, 2 points are notable. First, as summarized in Fig. 4, all the phrases found in one region were not necessarily included in every song from that region, and the likelihood of a particular phrase appearing varied between regions. For example, Theme 2 (yellow) is found in all 3 sessions from the Philippines, in 3 of 4 from Japan and in only 4 of 9 in Hawaii. Also the 'hybrid' themes recorded in Hawaii were only heard in 2 of the 9 singers from that region. Second, a prominent feature of the 2006 song in all regions was the 'greater'
Theme 5 (green) with its 4 variants, discussed in detail below. Fig. 3 also illustrates the repetitive and alternating relationship between some phrases and phrase variants.

\section{Order of phrases}

The order or pattern of phrases in the song cycle was similar in the Philippine, Japan and Hawaii samples, broadly shown in Fig. 3 and with examples in Fig. 5. All songs but one 'began' with Phrase 1 (purple), designated as such because it was usually the first theme sung as the whale dove after a breath sequence. (In the one song that did not include Phrase 1 the whale went quiet after its dive during the time period this phrase would be expected, then started with the next theme.) Phrase 2 (yellow) followed Phrase 1 in all cases but one whenever Phrase 2 was included in the song cycle. In all regions some singers skipped Phrase 2 (yellow) going directly from Phrase 1 to subsequent phrases. Then, in all 3 regions, much variability in the order and degree of alternation and repetition ensued between Phrases 3 (orange or brown), 4 (red), and 5 (greens), before consistently reaching Phrase 6 (blue) and the end of the song cycle. The cycle then repeated starting with Phrase 1 again. That is, with a few exceptions, all regions were similar with the alternation and repetition of phrases 3, 4 and 5 (and variants) between straight-order phrases 1, 2 and 6 .

The mid-song disorder consistent across regions is in itself a point of comparison, as this is not a universal characteristic of humpback whale songs. A singer can, and often does, make one-way progress from
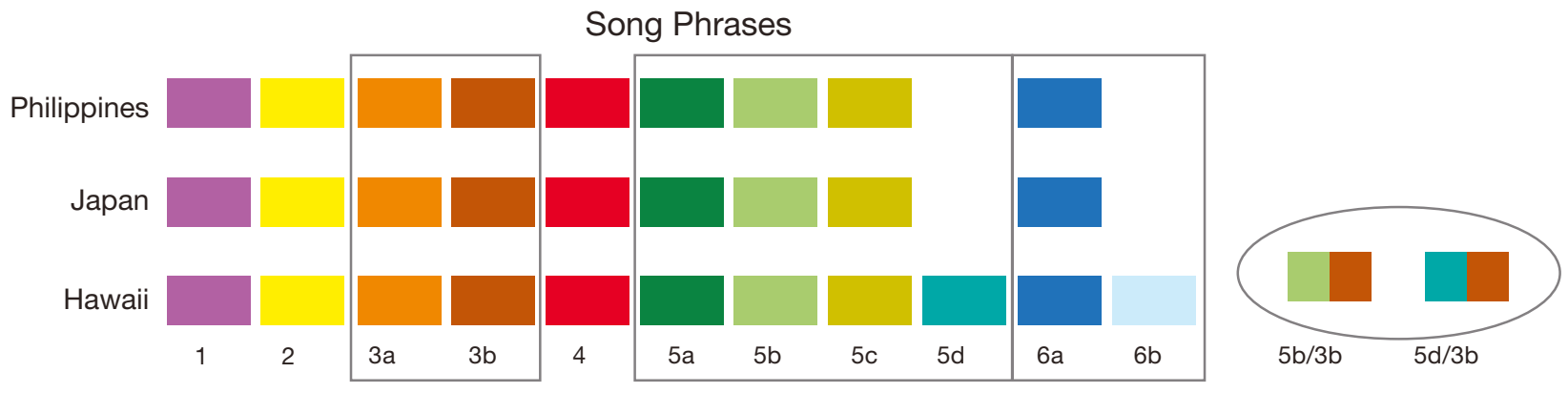

American Samoa

AS1 AS2a AS2b AS3 AS4

Fig. 2. Phrases found in Philippine, Japan, Hawaii and American Samoa song samples in 2006. Each color and its alphanumeric represents the distinct phrases (and phrase variants) present in the sample of songs from each region. The boxes surround variants of one phrase; the oval the 2 hybrid phrases found only in the Hawaii sample. The gray shades indicate that the phrases composing the American Samoa (South Pacific) song were different from those in the North Pacific. The spectrograms that form the basis for the categorization are provided in the Appendix 

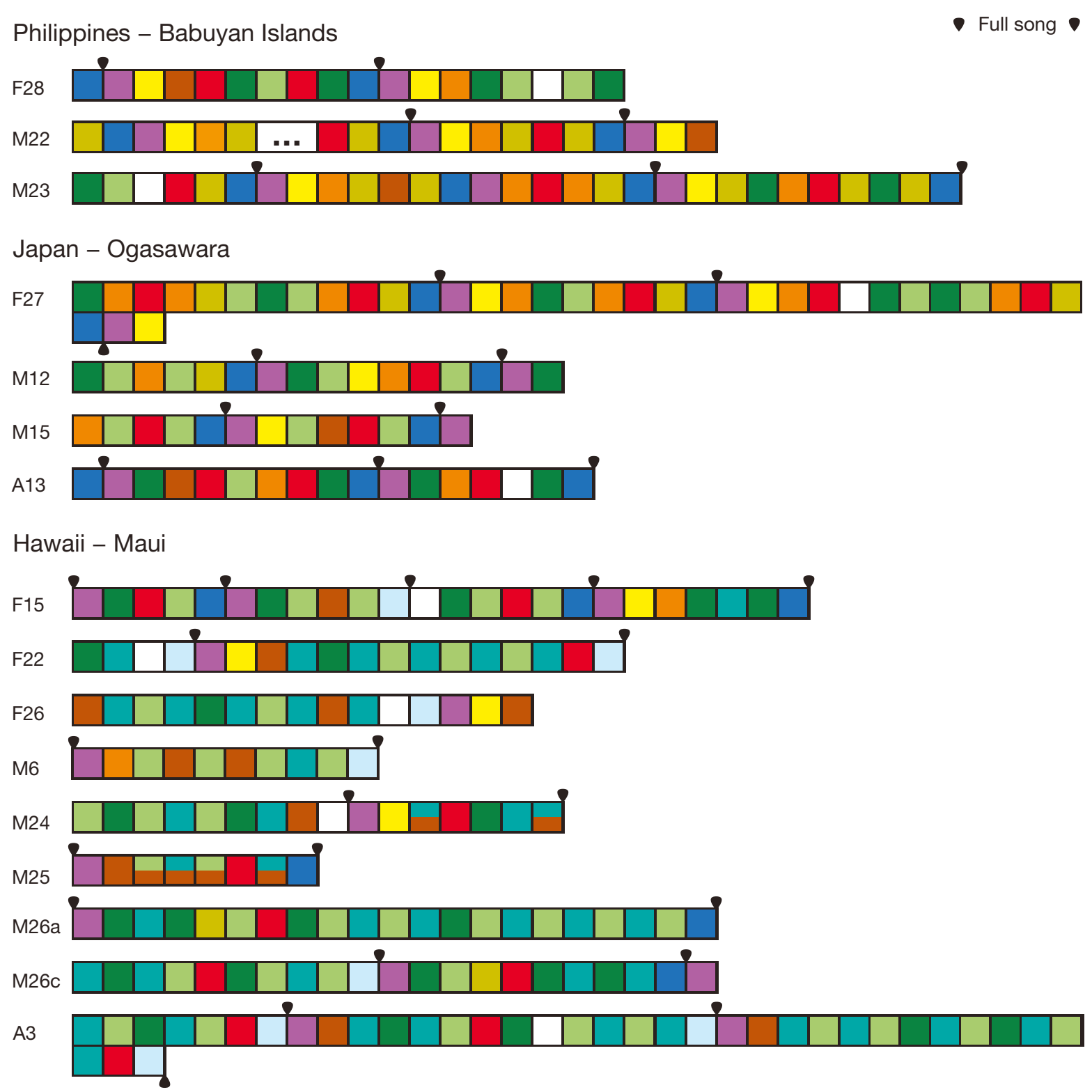

Fig. 3. The composition of all the songs used in the comparative analyses from the Philippines, Japan and Hawaii in 2006. The phrases composing the songs from each region are represented by the color bars (see Fig. 2). This figure shows the presence, order and number of shifts between phrases; it does not indicate the length of song, or proportion of each phrase in the song. The white spaces indicate either a brief segment where sounds were not recognized (designated as 'other') or a whale briefly stopping singing (for $<30$ s) or in 1 case, Philippines M22, a break in the recording (note the song this occurred in was not used in full song analyses)

one theme to another in straight order with no reversals, then repeat the cycle. This is illustrated in Fig. 5 with examples of the 2006 song from American Samoa and another from Hawaii in 1999. In the current North Pacific sample, the most alternation and repetition occurred in each region between the different phrases with more than 1 variant and between the multiple variants of 1 phrase.

Beyond this similarity across regions, there were some fine-scale differences in order tendency. For example, the most common alternating phrases or phrase variants differed between Hawaii and the Asian populations. In Hawaii, 46\% (74 of 161) of phrase changes were between the related Theme 5 (green) variants compared with only $11 \%$ in both Japan (9 of 79) and Philippines (7 of 62). On the other hand, in Asian locations there was more reversal between Themes 3 (orange/brown) and 4 (red) (6\% of changes in Philippines and $13 \%$ of changes in Japan) than in Hawaii $(0 \%)$. 


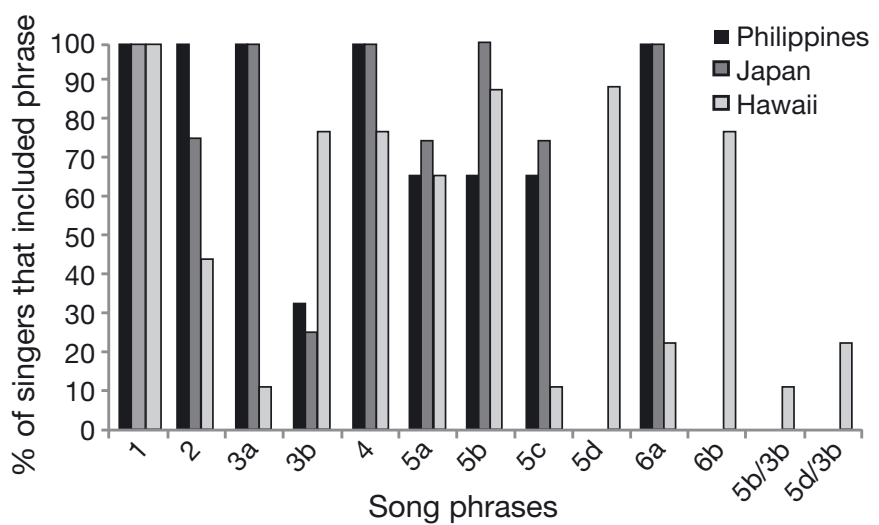

Fig. 4. Relative use of specific phrases in the Philippine, Japan and Hawaii 2006 song samples. The percent of the singers that included specific phrases varied between regions. For example some phrases (e.g. Phrase 1) were recorded from every singer in all 3 regions, other phrases were presented by every singer in 1 or 2 regions but not all 3 , and some phrases were used by only a few singers in 1 region, or were not present at all

\section{Percentage of song dedicated to different phrases}

Phrases are not given equal time in a song cycle. The repetition of one phrase may occur over a large portion of the duration of the song, while other phrases may occupy much smaller portions of the cycle. The mean percent of the song dedicated to each phrase for each region is illustrated by the pie charts in Fig. 6 .

There is a marked similarity between the regions in the proportion of some phrases, and some contrast in the proportion of others (Fig. 6). For example, Phrase 1 (purple) and Phrase 2 (yellow) had a range of only $3 \%$ difference between the 3 regions, Phrase 4 (red) had a range of $12 \%$ between regions, but in all 3 it was the most common phrase in the song. At the other end of scale, Phrase 5d (teal) was not found at all in the Asian populations, but comprised $21 \%$ of the song in Hawaii. Table 2 provides a narrative of phrase use in each region.

A correlation analysis investigated the degree of similarity between specific phrase 'use' in the 3 regions. Although the sample size is small, some of the correlations reached statistical significance. The Pearson's correlation of song composition was high between the Philippines and Japan ( $\mathrm{r}=0.876$, $\mathrm{p}<$ $0.001)$, but moderate between Japan and Hawaii ( $\mathrm{r}=$ 0.583, $\mathrm{p}=0.029$ ) and Philippines and Hawaii ( $\mathrm{r}=$ $0.570, p=0.033$ ), suggesting that the degree of difference in songs may be correlated with the degree of separation of singers. The Japan and Philippine study areas are separated by $2300 \mathrm{~km}$, Japan and Hawaii by $6200 \mathrm{~km}$, and Philippines and Hawaii by $8400 \mathrm{~km}$.

\section{Phrase 5 variants and finer-scale comparison}

A consistent difference in the songs between regions concerned the presence and/or proportion of specific Phrase 5 variants ( 5 a to $5 d$ ). The Fig. 7 pie charts illustrate the differences in the use of these variants between regions. In the Philippines, the highest phrase use was $5 \mathrm{~b}(43 \%)$; in Japan, the highest use was $5 \mathrm{a}$
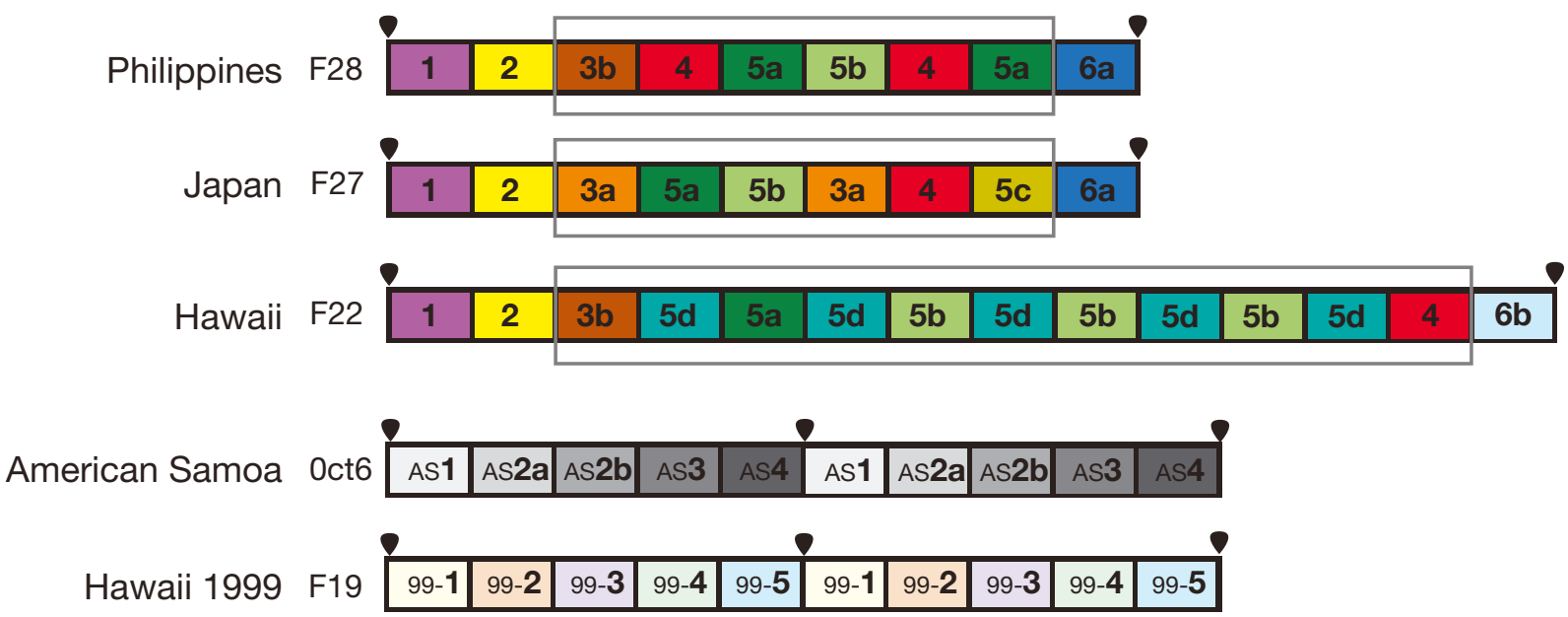

Fig. 5. Examples of the order of phrases in songs recorded from the 3 regions, Philippines, Japan and Hawaii in 2006. The midsong (within boxes) disorder in all 3 North Pacific 2006 examples is not necessarily characteristic of humpback song, with the straight progression from one phrase to another as shown in the American Samoa (2006) and Hawaii (1999) songs also a common pattern. Two cycles of each of the American Samoa and Hawaii songs are illustrated. Note that the figure does not indicate the length of songs, only the number of shifts between phrases; the longer the color bar the more shifts occurred 

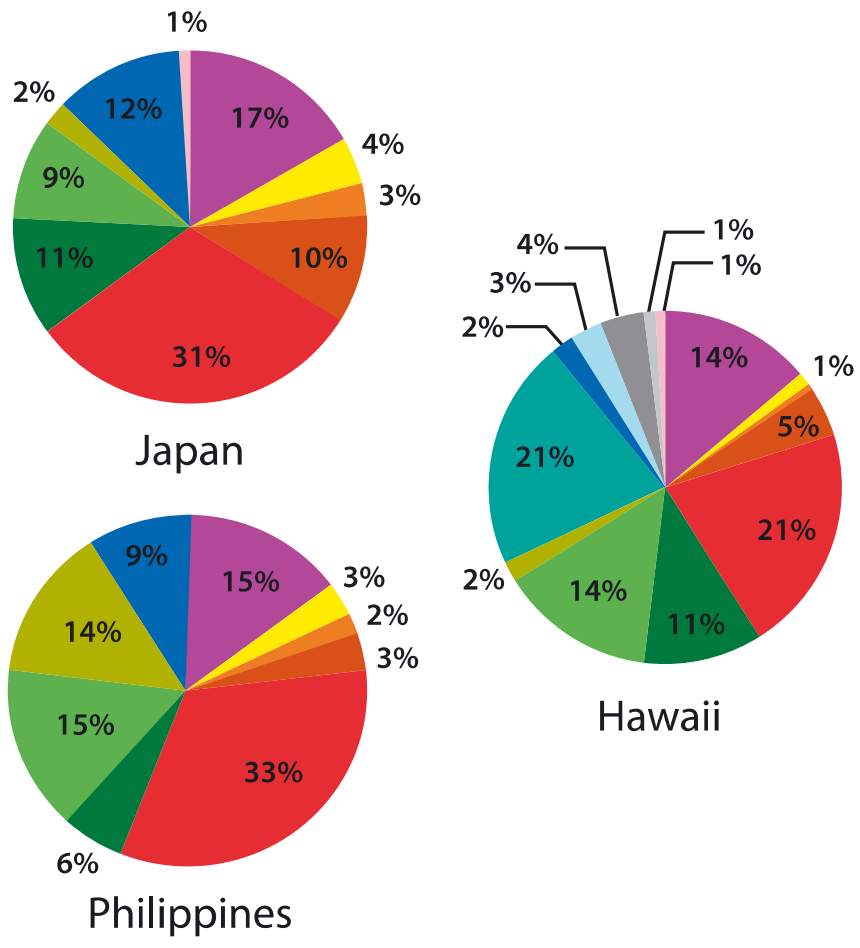

Hawaii
$123 a \quad 3 b \quad 4$ 5a 5b 5c 5d 6a 6b 5d3b 5b3b other

Fig. 6. Comparison of relative phrase use in the song samples from the 3 regions, Philippines, Japan and Hawaii, in 2006. The percent of the song sample dedicated to each phrase in each region is indicated. At this scale of comparison, the Japan and Philippines singers used all the same phrases but not in the same proportion, while Hawaii differed in both proportion and unique phrases

(50\%); and in Hawaii, the highest use was 5d (44\%). Also in Fig. 5, it is clear that the proportions of the 5c variant differ substantially between the 3 regions, with it occupying $40 \%$ of Theme 5 in the Philippines, $9 \%$ in Japan and $4 \%$ in Hawaii.

The Phrase 5c variant was, as noted in the 'Materials and methods', a unique case with 3 different versions clumped in the analysis so far. It arose from the modification of sound units different from the other Phrase 5 variants. Consider that Phrase 5 consists of 4 different units of sound. The variants $5 \mathrm{a}, 5 \mathrm{~b}$ and $5 \mathrm{~d}$ were the result of changes and differences in the second sound unit (i.e. $5 \mathrm{a}=1,2,3,4 ; 5 \mathrm{~b}=1,5,3,4 ; 5 \mathrm{~d}=$ $1,3,4)$. In contrast, the $5 \mathrm{c}$ variant was the result of joining sound units \#3 and \#4. Therefore, the possible combinations (of the 2 different sites of change) multiply to include: a 5 a version of $5 \mathrm{c}(1,2,3-4)$, a $5 \mathrm{~b}$ version of $5 c(1,5,3-4)$, and a $5 d$ version of $5 c(1,3-4)$. These different versions of Phrase $5 \mathrm{c}$ variant are indicated by cross-hatching above the $5 \mathrm{c}$ olive color in Fig. 7.
Table 2. Summary of the relative use of specific song phrases in the Philippines, Japan and Hawaii in 2006

$\begin{array}{ll}\text { - Phrase 1: } & \begin{array}{l}\text { a clear consistent phrase (present in } \\ \text { songs), in similar proportion across al } \\ \text { - Phrase 2: }\end{array} \\ & \begin{array}{l}\text { a commons. } \\ \text { all songs), occupying a similar small } \\ \text { portion of the sample from all } 3 \\ \text { regions. }\end{array}\end{array}$

- Phrase 3a: present in all regions (but not all songs), occupying a similar small portion of the sample in the Philippines and Japan; heard once in the Hawaii sample.

- Phrase 3b: present in all regions (but not all songs), occupying a relatively small $(<10 \%)$ portion of the song in all regions, but showing some variability between regions.

- Phrase 4: $\quad$ was a clear consistent phrase in all regions (present in all songs except 2 from Hawaii), and the largest proportion of the sample in all regions unless Phrase 5 variants were combined.

- Phrase 5a: a clear consistent phrase in all 3 regions (in all songs except for 1 from Philippines and 2 from Hawaii); occupying a lesser portion of the song in the Philippines.

- Phrase 5b: a clear consistent phrase found in all 3 regions (but not all songs), occupying a lesser portion of the song in Japan.

- Phrase 5c: present in all regions (but not all songs); however, it was most common in the Philippines while a relatively small proportion of the song in Japan and Hawaii.

- Phrase 5d: was the dominant Theme 5 variant in Hawaii, and not present in either of the Asia samples.

- Phrase 6a: was present in all regions (but not all songs in Hawaii), with similar relatively larger proportions in both Asia locations but poorly represented in the Hawaii sample. The difference between $6 a$ and $6 b$ is a single repetition of one of the 2 units in the phrase.

- Phrase 6b: present only in the Hawaii sample, occupying a relatively small portion of song.

- Hybrid 5b/3b: present only in the Hawaii sample (in 2 out of 8 songs), occupying a very small portion of the sample.

- Hybrid 5d/3b: present only in the Hawaii sample (in 2 out of 8 songs), occupying a very small portion of sample.

- Other: $\quad$ In both Hawaii and Japan very small portions $(1 \%)$ of the sample are either quiet (singer stops singing for period of seconds) or made up of sounds that could not be categorized as defined phrases (white spaces in Fig. 3). 

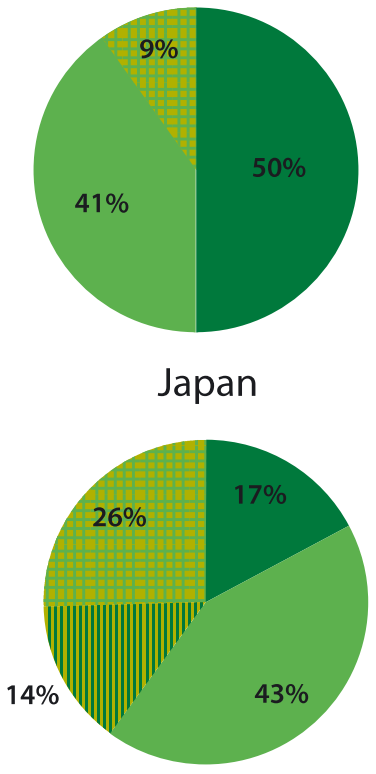

Philippines

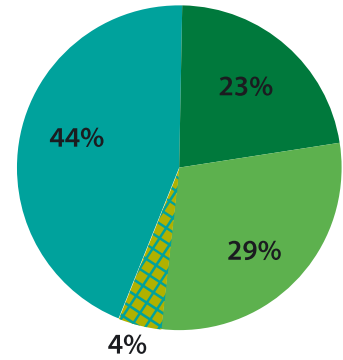

Hawaii

Fig. 7. Comparison of the relative use of Phrase 5 variants between the 3 regions, Philippines, Japan and Hawaii, in 2006. The use of the different Phrase 5 variants (a to d) in each region is indicated by the colors. A finer-scale comparison of the use of the different versions of the Phrase $5 \mathrm{c}$ variant is illustrated by the cross-hatching on top of the $5 \mathrm{c}$ olive color

If analyzed using this finer scale, these different versions of Phrase 5c variant could modify the result that the 2006 Philippine and Japan songs share all the same sound patterns. The Philippine sample included both the $5 \mathrm{a}$ version of $5 \mathrm{c}(5 \mathrm{c}-\mathrm{a})$ and the $5 \mathrm{~b}$ version of $5 \mathrm{c}(5 \mathrm{c}-\mathrm{b})$ with the proportion of the latter $(26 \%)$ double that of the former $(14 \%)$, while Japan included only the $5 b$ version $(5 c-b)$. That is, the Philippine sample included 1 fine-scale sound pattern (5a-c) not heard in the Japan sample. The Hawaii sample only included 1 version of 5c (5c-d), which was not found in the other locations. Considering the small sample and subtlety of difference, these Phrase $5 \mathrm{c}$ versions were documented but not emphasized in this comparison.

\section{DISCUSSION}

\section{Relationship of North Pacific humpback populations based on song composition}

\section{Similarities}

Humpback whale songs from winter assemblies in Hawaii, Japan and the Philippines in 2006 were

markedly similar in composition - that is, in the presence, order and proportion of the complex, changing sound patterns. The only likely explanation, as has been proposed in previous examinations (Helweg et al. 1990, Darling \& Mori 1993, Acebes et al. 2007), is that individuals, at least males, in these westerncentral Pacific populations mix at some point in their annual migratory cycles and songs are aligned. In contrast, the humpback whale song from American Samoa in the South Pacific, had no elements in common with the North Pacific samples. These populations are separated by hemisphere and not expected to mix.

Other studies have shown that Hawaii song is also very similar to eastern Pacific (Mexican) populations (Winn et al. 1981, Payne \& Guinee 1983, Cerchio et al. 2001). This study, combined with the earlier reports, indicates the mixing of humpback whales throughout the North Pacific basin-an area in the order of 60 million $\mathrm{km}^{2}$. The song similarity further suggests a degree of social coherence amongst humpback whales throughout the North Pacific.

Presumably, the maintenance of the common song occurs through the interchange of individuals and/or an overlap (at least acoustically) in the distribution of whales utilizing separate geographic locations around the North Pacific. Photo-identification matches and tagging studies clearly indicate the potential for mixing of whales throughout the North Pacific basin. This includes specifically all 3 regions in this study (Darling \& Cerchio 1993, Salden et al. 1999, Acebes et al. 2007, Calambokidis et al. 2008) as well as between these areas and the rest of the North Pacific (Nishiwaki 1966, Darling \& Jurasz 1983, Darling \& McSweeney 1985, Baker et al. 1986, Darling et al. 1996, Gabriele et al. 1996, Mate et al. 2007, Calambokidis et al. 2008). One question that arises is whether or not the whales in these studies that changed breeding grounds or moved to distant regions are exceptions to a rule of fidelity to specific grounds and shortest migratory routes, or whether they are more the norm, reflecting a significant panNorth Pacific homogeneity as indicated by maintenance of similar song.

\section{Differences}

While the clear conclusion of the song comparison is a North Pacific-wide integration of whales in some form, this study found fine-scale differences that may reflect short-term isolation of the breeding assemblies or other factors. 
This study's results are consistent with those earlier comparisons of humpback whale songs between the Asian populations and Hawaii that found them to be very similar but with a difference of 1 (Darling \& Mori 1993), 2 (Acebes et al. 2007) or 3 (Helweg et al. 1990) themes. Perhaps the most obvious comparison point in this study is that, of the total 13 phrases identified in the central-western Pacific sample, the same 9 were shared by the Japan and Philippines, while Hawaii had these 9 plus 4 more. Two of these 4 additional phrases were relatively minor, occurring in just 2 of 9 songs. The biggest difference between the Asia and Hawaii songs were 2 phrase variants common in the Hawaii $(5 d, 6 b)$ but not found in the Asian songs - with only the former (5d) really substantial, comprising $21 \%$ of the Hawaii sample. Thus this analysis agrees more or less with earlier comparisons.

It is important to emphasize that the 'differences' between regions described in this study are very small relative to the song overall. The difference between the Philippine and Japan samples, which had all 9 phrases in common, was only in the relative amount of time a specific phrase was used (unless one goes to a very fine-scale level of compound variants, as described for Phrase 5c). In the collective Asian versus Hawaii comparison, the difference leading to the 'extra' phrases described above was at most (1) the absence of just 1 sound unit in 1 or 2 phrases of the song or (2) the intermix of units from 2 existing phrases as a hybrid.

Whether or not these relatively subtle differences compared with overall song similarity were significant to the whales remains an open and relevant question. Possible support for significance is that the unit-scale differences were consistent across singers in a sample (that is, not just a slip-up by 1 singer). If, as surmised, overall song change occurs (in North Pacific at least) incrementally with small changes heard and incorporated by a neighbor, it seems intuitive that temporary isolation of a singing group from the larger song pool should lead to, initially at least, small differences.

The Hawaii song sample could be interpreted as more 'complex' than the Asia song. Potential factors here include the substantially larger population size in Hawaii (approximately 8000 to 10000 whales) versus the Asia regions (approximately 1000) (Calambokidis et al. 2008). Also it is possible that the eastern North Pacific humpbacks in Mexico and Central America (approximately 6000 to 7000 whales) may have more influence on the Hawaiian song, that is, adding elements that may not reach the more distant Asia populations.
Divergence and convergence

In their comparison of songs between Mexico and Hawaii, Cerchio et al. (2001) emphasized the similarity, but noted some minor divergence in composition of the songs as the winter season progressed-presumably caused by the temporary isolation of the breeding ground assemblies. It is likely that the differences in song between the Philippines and Japan, and more so between either of these locations and Hawaii, are the result of the same dynamic-seasonal winter separation of the populations combined with the continuing song change and adoption of changes by nearby associates only.

Equally intriguing is the re-convergence of the song that must occur at some point during the rest of the year. If this did not occur-based on our understanding to date-the songs would continue to diverge and result in entirely different songs in each of this study's regions; clearly not the case. Songs essentially identical in composition were reported between Mexico and Hawaii in the years 1977, 1978, 1979 and 1991 (Winn et al. 1981, Payne \& Guinee 1983, Cerchio et al. 2001); and highly similar songs reported between Japan and Hawaii for 1988 (Darling \& Mori 1993), Philippines and Hawaii in 2003 (Acebes et al. 2007), and for both regions and Hawaii in 2006 (this study). Again, Helweg et al. (1990) reported somewhat larger differences in 1989 songs between Japan, Hawaii and Mexico than all the other studies.

How, where or why the convergence in song composition occurs is not known. However, there is now ample evidence that singing occurs during migrations and on feeding grounds (e.g. Mattila et al. 1987, McSweeney et al. 1989, Clapham \& Mattila 1990, Noad et al. 2000, Gabriele \& Frankel 2002, Clark \& Clapham 2004, Stimpert et al. 2012, $\mathrm{Vu}$ et al. 2012). Song convergence does suggest a substantial degree of mixing, or perhaps some form of serial boundary transmission of song, throughout the North Pacific. It is possible that the differences in song found in winter assemblies may be the result of a combination of divergence during temporary isolation and incomplete convergence the previous summer.

\section{Migratory pattern}

These song comparisons may offer insight into migratory behavior. This assumes the scenario we have adopted actually occurs, that is (1) there is a 
separation of migratory pathways at some point leading to some degree of isolation of winter assemblies and (2) that song changes are adopted by nearby whales as a result of hearing the song.

The best-fit picture of migratory behavior using only this 2006 song comparison is a 'pool' of common song first divides into 2, 1 stream moving toward Asia and 1 moving toward Hawaii, and then later in time the Asian stream splits again, with one subpopulation staying in Ogasawara and the other continuing towards the Philippines. This 2-stage divergence of the migratory stream would explain the uneven differences in the song, with the lesser difference between the Asian populations as a result of later and lesser degree of separation than the Hawaiian stream. Current photo-identification matches support this scenario with withinseason interchange of whales between Japan and Philippines documented (Acebes et al. 2007), while (so far) only between-season interchanges have been found between Asia and Hawaii (Darling \& Cerchio 1993, Salden et al. 1999, Calambokidis et al. 2008).

\section{Degrees of similarity and their use as an index of association}

Full versus partial similarity

Most earlier song comparisons, coincidentally it seems, were between regions that had either the entire song composition in common or nothing the same (Winn et al. 1981, Payne \& Guinee 1983, Cerchio et al. 2001, Darling \& Sousa-Lima 2005). These studies led, reasonably, to the notion of the whole song as the functioning unit of the display or communication, with change working on all components simultaneously, or at least in a connected fashion. Even in Noad et al.'s (2000) example of rapid song change, it appears that the entire eastern Australia song was the object of change, and many of Garland et al.'s (2011) examples indicate full (rather than partial) song differences between South Pacific archipelagos.

The observations that songs can be partially the same, with some phrases in common and others unique (e.g. Murray et al. 2012, this study), substantially complicates this initial view of the song. Partial similarity indicates that some phrases comprising a song are more prone to change than others. This is consistent with Payne \& Payne's (1985) separation of Bermuda song into static versus shift- ing themes in which successive phrases evolve. That is, some phrases were stable and others more dynamic sites of change. Exactly how partial similarity in the songs of 2 populations arises is conceptually challenging. Presumably it goes something like this: if an assembly of whales has a song with phrases A, B, C, D, and B is more sensitive to change than the others, and the group diverges into different populations then-when forces of change are applied and at some later date-we might expect phrases $A, E, C, D$ in one population and $\mathrm{A}, \mathrm{F}, \mathrm{C}, \mathrm{D}$ in another. This is further complicated by the relative degree of sensitivity to change of each phrase in the song with the assumption that, if the populations do not converge again, they will all change eventually.

This dynamic may account for partially similar songs and make sense of other observations of substantial 'inequalities' in the phrases that make up a song as described in this analysis. For example, in any song there is great variability in: (1) the percent of the song that is dedicated to a specific phrase, (2) in the number of minor variants of a specific phrase, and (3) the likelihood of repetition or alternation with other phrases. Payne et al. (1983) commented that different variants of the same phrase type present in the same song and sung in an inconsistent and interchangeable sequence may be indicative of the evolution of a new theme. In other words, there is a more 'active' site in the song where innovation occurs. In this study, such a site would be Theme 5 with its 4 variants (as well as the $5 \mathrm{c}$ compound variants).

\section{Song as index of association}

Murray et al. (2012), in their examination of songs from Madagascar and Western Australia, made the assumption that a greater amount of shared song infers a greater degree of exchange and vice versaand in that example concluded that with just 1 of 5 themes in common the exchange would be relatively slight. However, these authors cautioned that 'a quantitative measure of exchange needed for complete song sharing vs. limited song sharing is still unknown.'

In this study, the sample of songs from the 2 closer regions, Philippines and Japan, showed a significantly higher correlation in composition (presence and proportion of phrases) than either of those locations with the song sample from Hawaii, 3 to 4 times more distant. That is, the degree of difference in song 
from one region to another appeared to be correlated with the distance apart, which is assumed to correlate with degree of isolation of the populations. This $1 \mathrm{yr}$ result is clearly not definitive; however, it is intuitive and consistent with Murray et al.'s (2012) assumption, and encourages further study along these lines.

There is, however, a substantial caveat in this exploration of use of song similarity as an index of association. It is that the pace of change in song is not necessarily consistent over time or across populations. This is true at the phrase level as described above (and is the only apparent explanation for partial song similarity), as well as at the song level (Payne \& Payne 1985, Noad et al. 2000, Garland et al. 2011). Obviously, if the rate of change-even for 1 phrase - is not consistent between the songs being compared, complications arise. The forces behind song change are not known, therefore it is impossible to predict at this time what factors may influence the rate of change of a song. Two contenders might be size of the isolated population and rate of immigration of whales with different song-and these factors may not be independent.

The possibility arises that 2 dynamics (at least) could determine the degree of song similarity: (1) the degree of separation of the populations, and (2) the relative sensitivity to change. That is, it seems possible to have a minor separation and great sensitivity to change, or a major separation and little sensitivity to change, with both circumstances resulting in the same degree of difference in song composition. This may complicate comparison of populations with different social circumstances that presumably govern song change.

Insight into patterns of song identity and change may come from comparisons of North and South Pacific humpback whale populations. In some contrast to the near common song of the entire North Pacific, insular populations around different archipelagoes in the southwest Pacific-separated by substantially less distance than the North Pacific breeding assemblies - may have entirely different songs between them (Garland et al. 2011, 2013). Also, in contrast to the typically slowly evolving North Pacific song, song composition in any one South Pacific region may change completely from one year to the next (Noad et al. 2000, Garland et al. 2011). Are the distinctive songs and rapid pace of change in the southwest South Pacific a function of smaller populations in isolation and/or more fragmented habitat than that experienced by the large populations in the North Pacific who share an ocean basin and common song?
Similarity of song between winter assemblies in the central-western North Pacific indicates significant mixing at some point during annual cycles, with the range of difference in composition likely reflective of the duration of seasonal acoustic isolation. While the degree of difference in song may correlate to the degree of separation of populations in some circumstances, potential variability in the rate of change of components (or indeed whole song) may complicate its use as an index of association on a broad scale. An array of unknowns hinder this investigation, including little or no understanding of the mechanics of, or forces behind, song change, or indeed the purpose of the singing behavior.

Acknowledgements. We wish to acknowledge all those who assisted and supported the 4 studies that allowed this song comparison. We thank: in the Philippines WWF-Philippines, Bureau of Fisheries and Aquatic Resources - Region 2, Department of Environment and Natural Resources - Region 2, Local Government Unit of the Municipality of Calayan; Elson Aca, Jose Mari O. Daclan, Cynthia Layusa, Crissy Canlas, Grazen Acerit, Freya Adamczyk, Gabriel Timoteo, A. G. Saño and Hussein Macarambon; in Ogasawara, all those who supported and assisted M.Y.; in Hawaii, Whale Trust, including Meagan Jones, Flip Nicklin and Jason Sturgis and the many volunteers and local supporters that enabled and assisted in the 2006 field work. We are especially grateful to David Mattila, Hawaiian Islands Humpback Whale National Marine Sanctuary and Jooke Robbins, Center for Coastal Studies, for providing the song recordings from American Samoa. Thanks are due to Erin Linn McMullan for editing drafts of the manuscript and Barbara Schramn for the graphics. The study in Hawaii and song comparison was funded by Whale Trust. The research in Hawaii was conducted under NMFS Scientific Permit \#753.

\section{LITERATURE CITED}

Acebes JV, Darling JD, Yamaguchi M (2007) Status and distribution of humpback whales (Megaptera novaeangliae) in northern Luzon, Philippines. J Cetacean Res Manag 9: $37-43$

Baker CS, Herman LM, Perry A, Lawton WS and others (1986) Migratory movement and population structure of humpback whales (Megaptera novaeangliae) in the central and eastern North Pacific. Mar Ecol Prog Ser 31: 105-119

Calambokidis J, Falcone EA, Quinn TJ, Burdin AM and others (2008) SPLASH: structure of populations, levels of abundance and status of humpback whales in the North Pacific. Final report for Contract AB133F-03-RP-00078, Cascadia Research Collective, Olympia, WA

> Cerchio S, Jacobsen JK, Norris TF (2001) Temporal and geographical variation in songs of humpback whales, Megaptera novaeangliae: synchronous change in Hawaiian and Mexican breeding assemblages. Anim Behav 62:313-329

> Cholewiak DM, Sousa-Lima RS, Cerchio S (2013) Hump- 
back whale song hierarchical structure: historical context and discussion of current classification issues. Mar Mamm Sci 29:E312-E332

Clapham PJ, Mattila DK (1990) Humpback whale songs as indicators of migration routes. Mar Mamm Sci 6:155-160

Clark CW, Clapham PJ (2004) Acoustic monitoring on a humpback whale (Megaptera novaeangliae) feeding ground shows continual singing into late spring. Proc R Soc Lond B 271:1051-1057

Darling JD, Cerchio S (1993) Movement of a humpback whale (Megaptera novaeangliae) between Japan and Hawaii. Mar Mamm Sci 9:84-91

Darling JD, Jurasz CM (1983) Migratory destinations of North Pacific humpback whales (Megaptera novaeangliae). In: Payne R (ed) Communication and behavior of whales. AAAS Selected Symposia Series. Westview Press, Boulder, CO, p 359-368

Darling JD, McSweeney DJ (1985) Observations on the migrations of North Pacific humpback whales (Megaptera novaeangliae). Can J Zool 63:308-314

Darling JD, Mori K (1993) Recent observations of humpback whales (Megaptera novaeangliae) in Japanese waters, Ogasawara and Okinawa. Can J Zool 71:325-333

Darling JD, Sousa-Lima RS (2005) Songs indicate interaction between humpback whale (Megaptera novaeangliae) populations in the western and eastern South Atlantic Ocean. Mar Mamm Sci 21:557-566

Darling JD, Calambokidis J, Balcomb KC, Bloedel P and others (1996) Movement of a humpback whale from Japan to British Columbia and return. Mar Mamm Sci 12:281-287

Gabriele CM, Frankel AS (2002) The occurrence and significance of humpback whale songs in Glacier Bay, Southeastern Alaska. Arctic Res US 16:42-47

Gabriele CM, Straley JM, Herman LM, Coleman RJ (1996) Fastest documented migration of a North Pacific humpback whale. Mar Mamm Sci 12:457-464

Garland EC, Goldizen AW, Rekdahl ML, Constantine R and others (2011) Dynamic horizontal cultural transmission of the humpback whale song at the ocean basin scale. Curr Biol 21:687-691

Garland EC, Gedamke J, Rekdahl ML, Noad MJ, Garrigue, C, Gales N (2013) Humpback whale song on the Southern Ocean feeding grounds: implications for cultural transmission. PloS ONE 8:e79422

Helweg DA, Herman LM, Yamamoto S, Forestell PH (1990) Comparison of songs of humpback whales (Megaptera novaeangliae) recorded in Japan, Hawaii and Mexico during winter of 1989. Sci Rep Cetacean Res 1:1-20

Helweg D, Cato D, Jenkins P, Garrigue C, McCauley R (1998) Geographic variation in South Pacific humpback whale songs. Behaviour 135:1-27

Mate BR, Mesecar R, Lagerquist B (2007) The evolution of satellite-monitored radio tags for large whales: one laboratory's experience. Deep-Sea Res II 54:224-247

- Mattila D, Guinee LN, Mayo CA (1987) Humpback whale songs on a North Atlantic feeding ground. J Mammal 68: 880-883

McSweeney D, Chu K, Dolphin WF, Guinee LN (1989) North Pacific humpback whale songs: a comparison of southeast Alaskan feeding ground songs with Hawaiian wintering ground songs. Mar Mamm Sci 5:139-148

> Murray A, Cerchio S, McCauley R, Jenner CS, Razafindrakoto Y, Coughran D (2012) Minimal similarity in songs suggest limited exchange between humpback whales (Megaptera novaeangliae) in the southern Indian Ocean. Mar Mamm Sci 28:E41-E57

Nishiwaki M (1966) Distribution and migration of the larger cetaceans in the North Pacific as shown by Japanese whaling results. In: Norris KS (ed) Whales, dolphins and porpoises. University of California Press, Berkeley, CA, p 171-191

> Noad MJ, Cato DH, Bryden MM, Jenner MN, Jenner CS (2000) Cultural revolution in whale songs. Nature 408:537

Payne RS, Guinee LN (1983) Humpback whale songs as an indicator of 'stocks'. In: Payne R (ed) Communication and behavior of whales. Westview Press, Boulder, CO, p 333-358

> Payne RS, McVay S (1971) Songs of humpback whales. Science 173:585-597

> Payne K, Payne RS (1985) Large scale changes over 19 years in songs of humpback whales in Bermuda. Z Tierpsychol 68:89-114

Payne K, Tyack P, Payne RS (1983) Progressive changes in the songs of humpbacks: a detailed analysis of tow seasons in Hawaii. In: Payne R (ed) Communication and behavior of whales. Westview Press, Boulder, CO, p 9-57

Salden DR, Herman LM, Yamaguichi M, Sato F (1999) Multiple visits of individual humpback whales (Megaptera novaeangliae) between the Hawaiian and Japanese winter grounds. Can J Zool 77:504-508

Stimpert AK, Peavey LE, Friedlaender LS, Nowacek DP (2012) Humpback whale song and foraging behavior on an Antarctic feeding ground. PLoS ONE 7:e51214

Vu ET, Risch D, Clark C, Gaylord S and others (2012) Humpback whale song occurs extensively on feeding grounds in the western North Atlantic ocean. Aquat Biol 14:175-183

Winn HE, Thompson TJ, Cummings WC, Hain J, Hudnall J, Hays H, Steiner WW (1981) Songs of the humpback whale: population comparisons. Behav Ecol Sociobiol 8: $41-46$ 
Appendix. Spectrograms of song phrases found in samples from the Philippines (P), Japan (J), Hawaii (H) and American Samoa. Phrase variants are those with a letter attached to the phrase number. Rows continue on following page. Note that at the end of the Hawaii row, one of the Hawaii hybrid phrases is placed above the other rather than just in the Hawaii (H) row (to maximize size in space available). The North Pacific and South Pacific (American Samoa) songs had no phrases in common
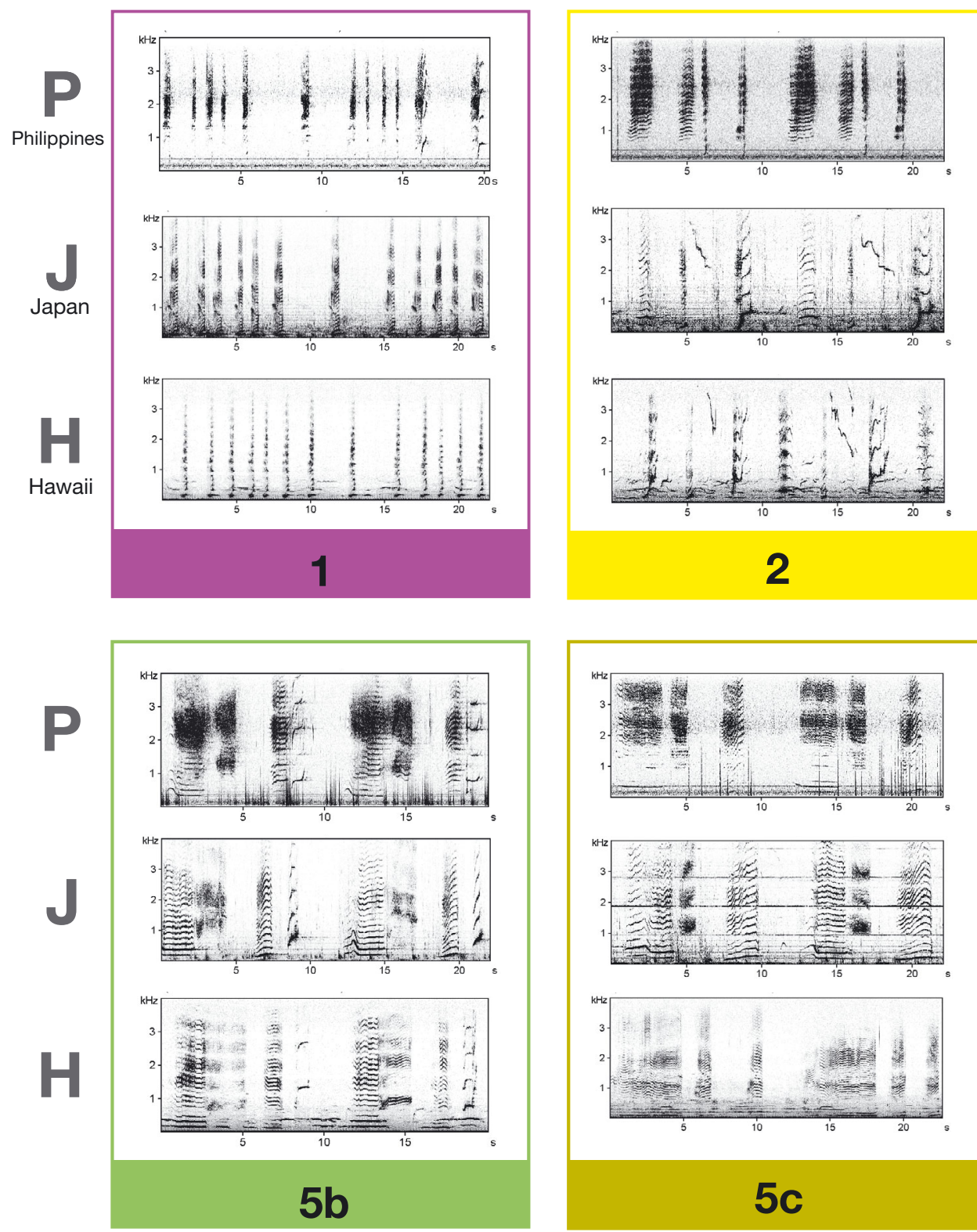

American Samoa

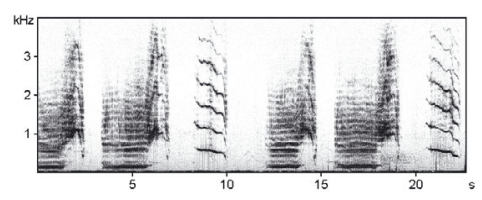

AS 1
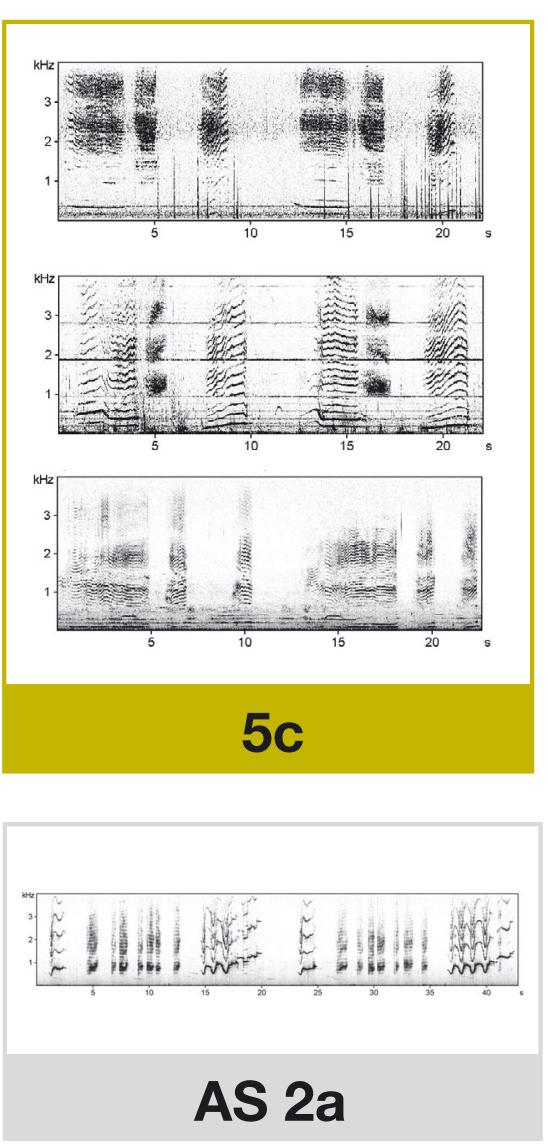
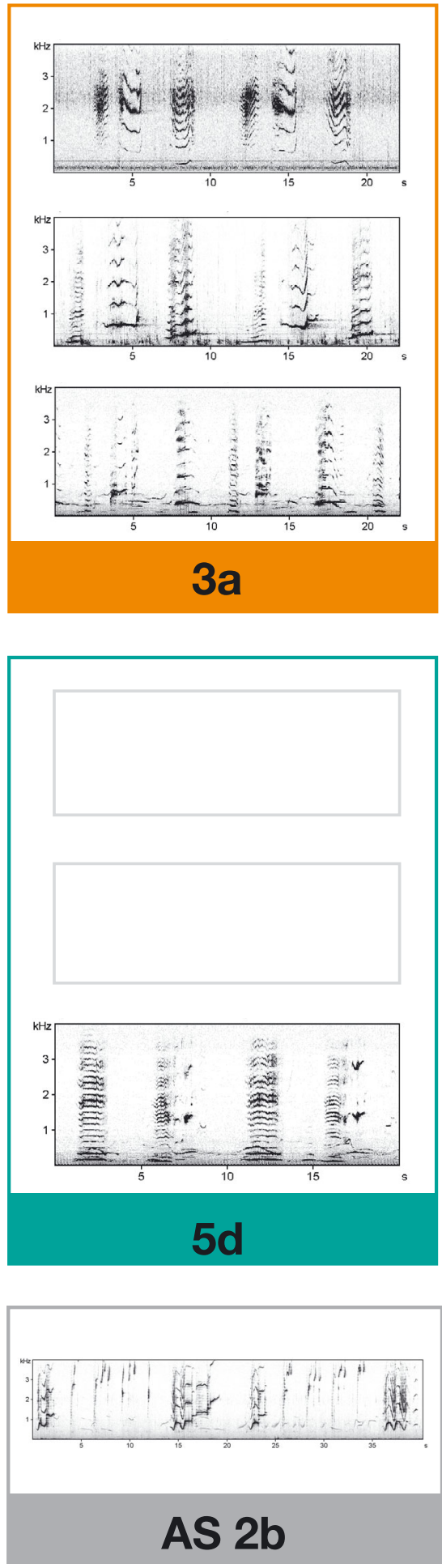

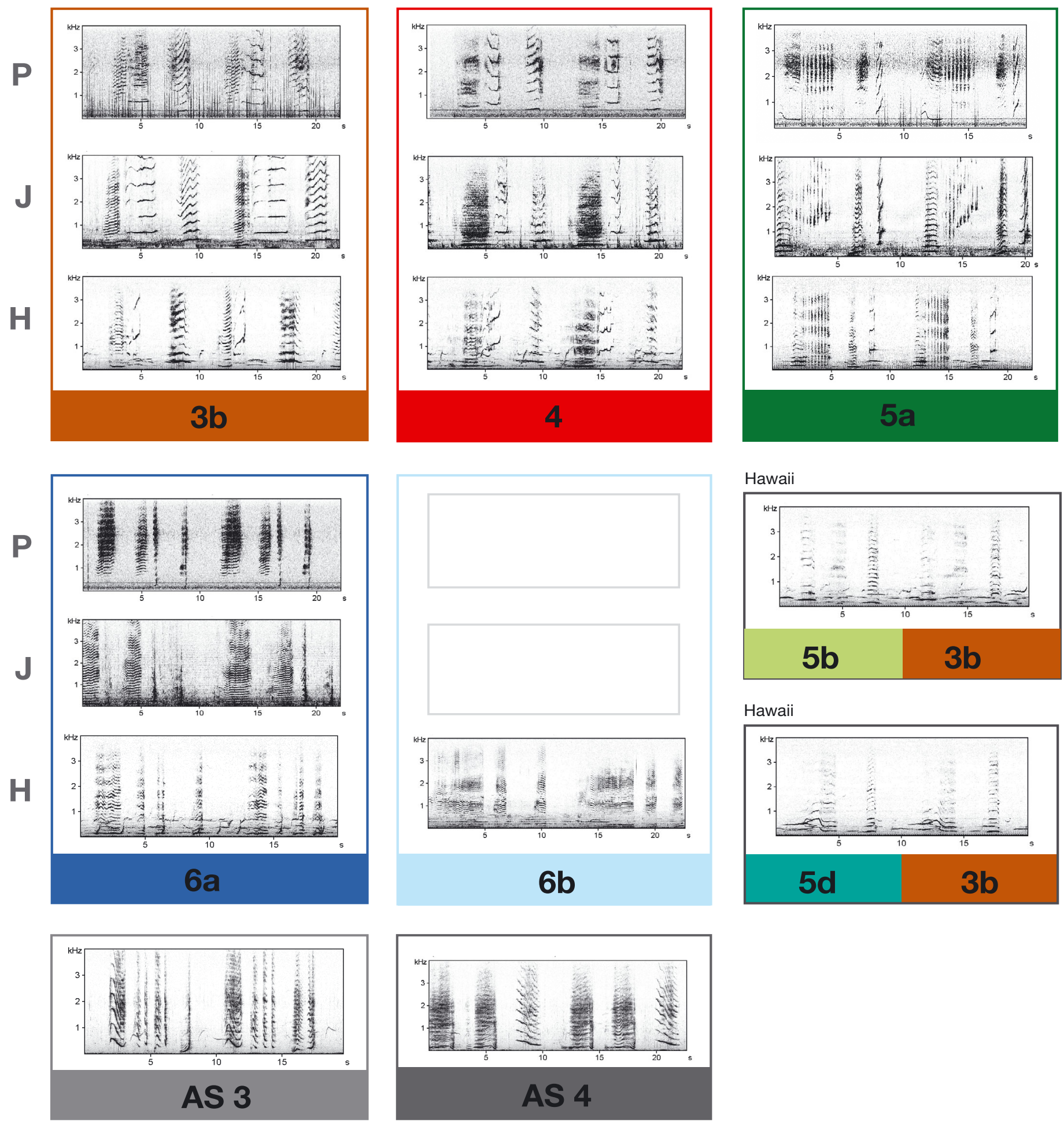

Editorial responsibility: Christine Paetzold, Oldendorf/Luhe, Germany 